\title{
Analysis on Side Slip Characteristics of Multi-axle Vehicle Tire
}

\author{
Ming Yang ${ }^{\mathrm{a}}$, Lingling $\mathrm{Li}^{\mathrm{b}}$ and Wenguang Zheng ${ }^{\mathrm{c}}$ \\ University of Science and Technology Liaoning, China \\ aannalily@126.com \\ blingling00@126.com \\ ${ }^{c}$ zwg2011@163.com
}

Keywords: Vehicle; Tire; side slip property

\begin{abstract}
Generally used tire model are Unitire model proposed by Academician Konghui Guo and MF-Tire model proposed by Professor Pacejka. In this paper, the tire model was for analyzing of handling stability of multi-axle vehicle. MF-Tire model was used to simulate the side slip characteristics of the multi-axle vehicle tire. Through simulation, the side slip properties of the multi-axle vehicle tire under different vertical load were obtained; the side slip properties of the multi-axle vehicle tire under different coefficient of road adhesion when $F_{Z}=50 \mathrm{kN}$ was analyzed.
\end{abstract}

\section{Introduction}

The tire model describes the tire component and the wheel motion parameters relations changes in the direction of six [1-4]. The domestic and foreign experts and scholars have established tire model under various conditions. Generally used tire model are Unitire model proposed by Academician Konghui Guo and MF-Tire model proposed by Professor Pacejka. Two models are all belong to the semi-empirical tire model. In which, MF-Tire model can simulate the relationship between the tires' aligning torque, longitudinal force and side force and motion parameters. Forty fitting parameters were contained. Unitire can simulate tire component in the direction of six. One hundred and seven fitting parameters were Contained roughly. The Unitire model simulation accuracy is higher compared to the other one, the suitable operating mode is more widely. But the Calculation of Unitire model is complex, cumbersome. In this paper, the tire model was for analyzing of handling stability of multi-axle vehicle. MF-Tire model was used to simulate the side slip characteristics of the multi-axle vehicle tire.

\section{Tire dynamics model}

The magic formula is tire model with the combination of trigonometric function formula to tyre test data fitting. Then, with a set of forms of the same formula can fully express the back of the tire is torque and tire longitudinal and lateral forces, so called "magic formula" model.

The general expression of the MF - Tire model is

$$
F_{Y}(X)=D \sin [C \arctan \{B X-E(B X-\arctan (B X))\}]+S_{V}
$$

In which,

$a_{i}$ — fitting coefficient;

$X=S_{h}+\alpha$

$\alpha$-Side-slip Angle; 
$X$ — the combination of the independent variable to a lateral force calculation;

$S_{h}$ - curve horizontal drift;

$S_{h}=a_{9} F_{Z}+a_{10}+a_{8} \gamma$

$F_{Z}$ - Wheel vertical load;

$S_{V}$ - curve vertical drift;

$S_{V}=a_{11} F_{Z} \gamma+a_{12} F_{Z}+a_{13}$

$E$ - Curve curvature factor;

$D$ - curve peak factor;

$D=a_{6} F_{Z}+a_{7}$

$\gamma$ _ camber Angle;

C - Curve shape factor;

$C=a_{0}$

$B$ — stiffness factor;

$B=B C D /(C \times D)$

$B C D$ — side force of the tire lateral stiffness to zero;

$B C D=a_{3} \sin \left(2 a \tan \left(F_{Z} / a_{4}\right)\right) \times\left(1-a_{5}|\gamma|\right)$

Considering the adhesion coefficient of road surface effect on the tire cornering characteristics, formula (1) can be written as

$$
F_{Y}(x)=\mu D \cdot \sin \left(C\left(\frac{5}{4}-\frac{\mu}{4}\right) \cdot \arctan ((2-\mu) B(1-E) \cdot x+E \arctan ((2-\mu) B \cdot x))\right)+S_{V}
$$

\section{Simulation}

This article uses the "magic formula" (MF - Tire) Tire model in 15 fitting coefficient is based on the values of the Tire in the ADAMS software module in the Tire model parameters of impact analysis, adjust some parameters.

Simulink module in the Matlab software environment according to the formula (2), tire lateral dynamics model is set up as shown in figure1.

The tire model input is the tire side-slip angle and tire vertical load, and the output is the side force. 


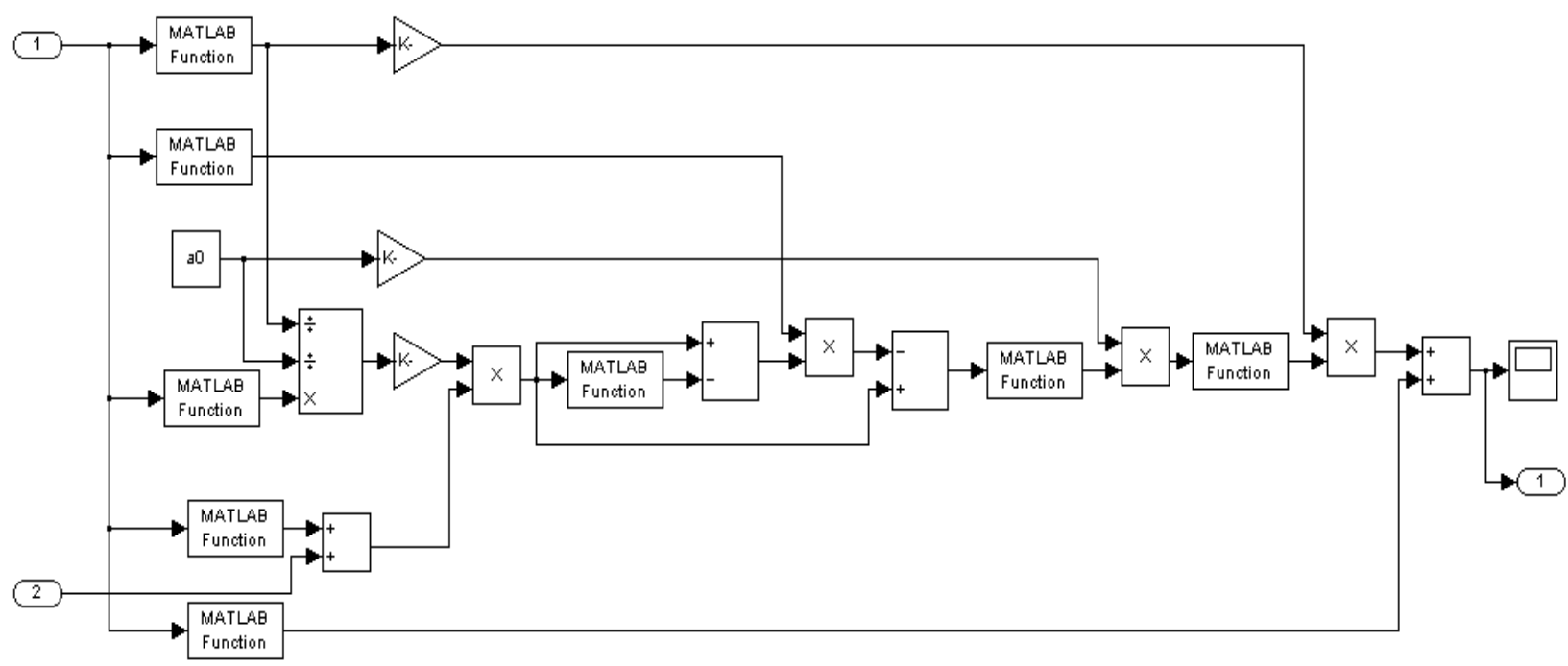

Fig.1 side force model

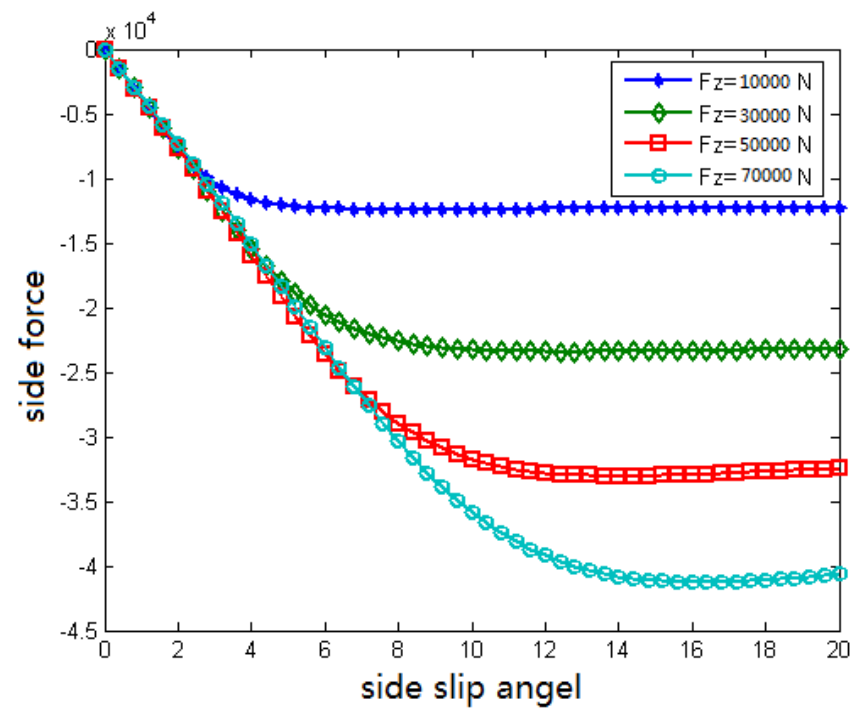

a. vertical load

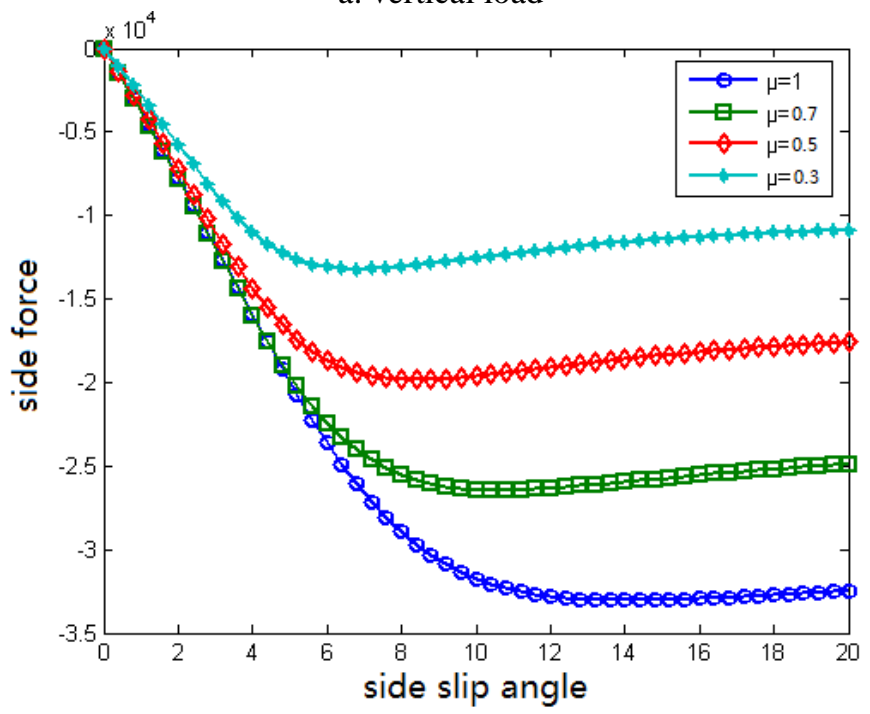

b. adhesion coefficient

Fig. 2 tire side slip properties curve 


\section{Conclusions}

Through the simulation of multi-axis vehicle tire under different vertical load of tire cornering characteristics curve as shown in figure 3 (a); Under the different road adhesion coefficient, when the vertical load of the tire for the multi-axle vehicle tire cornering characteristics of the curve, as shown in figure 3 (b).

It can be seen from the figure 3 that when the tire side-slip angle is small, the multi-axle vehicle tire present linear characteristic along with the increasing of side-slip angle value, tire lateral force of saturated at this point.

The tire appears nonlinear characteristics, and multi-axis vehicle tire cornering stiffness increases with the increasing vertical load and tire-road friction coefficient, and vice versa.

If you follow the "checklist" your paper will conform to the requirements of the publisher and facilitate a problem-free publication process.

\section{Acknowledgements}

This work was financially supported by the Education Department of Liaoning Province (L2012103).

\section{References}

[1] Konghui GuoQing Liu. Tire model used for vehicle dynamic analysis in stable conditions [J].

Vehicle Engineering, 1998, 20(3):129-134.

[2] E Bakker, L Nyborg, H B Pacejka. Tyre Modelling for Use in Vehicle Dynamics Studies [J]. SAE Paper, 1987, No. 870421

[3] Dingyu Xue, Yangquan Chen. Computer Aid Design of Control System using Matlab [M]. Beijing: Tsinghua Press, 2006.

[4] Huashi Li. Research on Multi-axle vehicle Steering properties [D]. Shandong Technology University, 2008.

[5]Daniel J. Buttars and James E. Bernard, Propagation of Error Applied to Linear Vehicle Dynamics[C]. SAE 2002 World Congress Detroit, Michigan March 4-7, 2002.

[6]Pinhas Barak, David-Peter Herczeg, Caleb Hollier, etc, Mathematical Modeling and Computer Simulation of a Passenger Vehicle Steering System, SAE TECHNICAL PAPER SERIES, 2004-01-0773.

[7]Nakashima H, Wong J Y.. Three-dimensional tire model by the finite element method[J]. Journal of Terramechanics,1993, 30(1): 21-34.

[8]Westermann Stefan, Petry Frank. Tire road contact mechanics[J]. VDI Berichte, 2007, 1(2014): 243-244.

[9]Olatunbosun O A, Bolarinwa O F E. Simulation of the effect of tire design parameters on lateral forces and moments[J]. Tire Science and Technology, 2004, 32(3): 146-163.

[10] Masato Abe. Simultaneous Optimal Distribution of Lateral and Longitudinal Tire Forces for the Model Following Control[J]. Journal of Dynamic Systems, Measurement, and Control, 2004, 126: 753-763. 